\title{
A library of IUE white dwarf spectra for stellar population analyses $^{\star}$
}

\author{
E. Bica, C. Bonatto and O. Giovannini \\ Universidade Federal do Rio Grande do Sul, IF, CP 15051, Porto Alegre 91501-970, RS, Brazil
}

Received October 30, 1995; accepted February 27, 1996

\begin{abstract}
We present high Signal to Noise ratio IUE spectra of different classes of white dwarfs, to be used as templates for stellar population analyses in the ultraviolet region. We present average stellar parameters associated to each group. The library contains 6 groups for DA's, 2 for DO's and 5 for DB's. We also present equivalent widths of spectral features, and continuum measurements. We call attention to the spectral characteristics which are promising indicators of the presence of white dwarfs in the spectra of composite stellar populations.
\end{abstract}

Key words: (stars): white dwarfs — ultraviolet: stars

\section{Introduction}

White dwarfs are not luminous objects, but they are very common: there are 1279 cataloged white dwarfs in McCook \& Sion (1987, hereafter MS87). Many of them have trigonometric parallaxes indicating distances below $100 \mathrm{pc}$ from the Sun. Since hot white dwarfs emit most of their light in the ultraviolet, it is in this spectral region where they can most probably be detected in spectra of composite stellar populations. In a recent paper, evidence was found of the presence of white dwarfs of type DA 5 in the spectra of early-type galaxies and globular clusters (Bica et al. 1996).

The International Ultraviolet Explorer (IUE) has been collecting spectra of white dwarfs for the last 17 years, and several of them already have a relatively large number of individual spectra stored in the IUE database.

Much information on stellar parameters have been derived from the IUE spectra of individual white dwarfs, just to mention a few: Wesemael et al. (1985) for DO's, Liebert et al. (1986) and Wegner \& Nelan (1987) for DB's, and Kepler \& Nelan (1993) and Bergeron et al. (1995) for DA's. A spectrophotometric atlas of individual white dwarfs was compiled from IUE archives by Wegner \& Swanson (1991).

In order to further explore this database, in the present paper we group stars of similar spectral characteristics into distinct white dwarf classes, which can be very useful for, e.g., stellar population analyses. We obtain template

Send offprint requests to: E. Bica

* Based upon data collected with the International Ultraviolet Explorer (IUE) Satellite, supported by NASA, SERC and ESA spectra of much higher signal to noise ratio $(S / N)$ than those of individual stars. This paper is structured as follows: in Sect. 2 we present the IUE white dwarf sample, gather information on individual stars from the literature, and measure fluxes in the present data; in Sect. 3 we build the groups and present the average parameters associated to them; in Sect. 4 we measure equivalent widths, continuum slopes and discuss the results; in Sect. 5 we present the concluding remarks of this work.

\section{The white dwarf sample}

We gathered the IUE spectra for the present sample from the IUE Uniform Low Dispersion Archive (ULDA Version 4.0) database as stored at the Instituto Astronômico e Geofísico of the Universidade de São Paulo (IAG-USP). Details on the ULDA calibration processes and access can be found in Courvoisier \& Paltani (1992, and references therein). Some obvious réseau marks and bad pixels have been corrected by a linear interpolation. The population synthesis of composite spectra such as those of galaxies and/or star clusters, requires the knowledge of the observational and theoretical parameters associated to the different stellar types. With this in mind, we searched for white dwarfs which had information on spectral classification and/or atmospheric parameters from the literature. The sample contains 86 white dwarfs, and is not intended to be complete in any sense: we gathered enough spectra in order to achieve a good $(S / N)$ for each group. We show the results for the individual early-type DA stars in Table 1 and for late-type DA's in Table 2, for DO's in Table 3 and DB's in Table 4. By Cols. (1) and (2) 
Table 1. Data on individual early-type DA stars

\begin{tabular}{|c|c|c|c|c|c|c|c|c|}
\hline WD\# & $\begin{array}{l}\text { Other } \\
\text { Names }\end{array}$ & $\begin{array}{l}\text { Spectral } \\
\text { Type }\end{array}$ & $\begin{array}{c}T_{\text {eff }}(\mathrm{K}) \\
\text { (Optical) }\end{array}$ & $\begin{array}{c}T_{\text {eff }}(\mathrm{K}) \\
\text { (UV) }\end{array}$ & $\log g$ & $M_{V}$ & $\begin{array}{c}10^{14} \times f_{\lambda}(2646) \\
\left(\mathrm{erg} \mathrm{cm}^{-2} \mathrm{~s}^{-1} \AA^{-1}\right)\end{array}$ & $\begin{array}{l}d_{\odot} \\
(\mathrm{pc})\end{array}$ \\
\hline & & & & & & & & \\
\hline $0136+251$ & PG 0136+251 & DA 1 & 34980 & & & 9.7 & 1.68 & $\dagger$ \\
\hline $0346-011$ & $\begin{array}{l}\text { GD } 50 \\
\text { GR } 228\end{array}$ & DA 2 & $\begin{array}{l}43102 \\
40540\end{array}$ & & 9.09 & $\begin{array}{l}11.4 \\
11.8\end{array}$ & 12.10 & 29.9 \\
\hline $0548+000$ & $\begin{array}{l}\text { GD } 257 \\
\text { GR } 289\end{array}$ & DA 1 & & & & 9.0 & 3.67 & 162.9 \\
\hline $0549+158$ & $\begin{array}{l}\text { GD 71 } \\
\text { LTT 11733 } \\
\text { EG 210 } \\
\text { L1241-036 }\end{array}$ & DA 1 & 33753 & 32800 & 7.76 & 9.3 & 21.90 & 56.5 \\
\hline $0612+177$ & $\begin{array}{l}\text { G104-27 } \\
\text { EG 46 } \\
\text { LTT } 11818 \\
\text { L1244-026 }\end{array}$ & DA 2 & $\begin{array}{l}25938 \\
24660\end{array}$ & & 7.97 & $\begin{array}{l}10.3 \\
10.4\end{array}$ & $\ddagger$ & 42.6 \\
\hline $1254+223$ & $\begin{array}{l}\text { EG } 187 \\
\text { PG } 1254+223\end{array}$ & DA 1 & 40432 & 41200 & 7.85 & 10.1 & 18.50 & 46.1 \\
\hline $1314+293$ & $\begin{array}{l}\text { HZ } 43 \mathrm{~A} \\
\text { PG } 1314 \\
\text { EG } 98\end{array}$ & DA 1 & 38200 & 50000 & 7.90 & 8.7 & 31.70 & 65.2 \\
\hline $1615-154$ & $\begin{array}{l}\text { G153-41 } \\
\text { LTT } 6497 \\
\text { EG } 118\end{array}$ & DA 2 & $\begin{array}{l}29833 \\
29730\end{array}$ & & 8.08 & 10.2 & 16.60 & 44.0 \\
\hline $1620-391$ & $\begin{array}{l}\text { GR 274 } \\
\text { CD-38 } 10980\end{array}$ & DA 2 & 24406 & 24800 & 8.10 & 10.6 & 116.0 & 12.0 \\
\hline $2014-575$ & L210-114 & DA & 28373 & & 7.88 & 10.0 & 11.60 & 40.2 \\
\hline $2111+498$ & $\begin{array}{l}\text { GD } 394 \\
\text { EG } 244\end{array}$ & $\begin{array}{l}\text { DA } 2 \\
\text { DA } 1.5\end{array}$ & 39450 & 37000 & & 9.3 & 26.40 & 55.0 \\
\hline $2309+105$ & $\begin{array}{l}\text { GD } 246 \\
\text { EG 233 } \\
\text { BPM 97895 }\end{array}$ & DA 1 & 57990 & 54000 & 7.91 & 11.1 & 28.20 & 25.1 \\
\hline $0047-524$ & $\begin{array}{l}\text { BPM } 16274 \\
\text { L } 219-48\end{array}$ & $\begin{array}{l}\text { WD_A2 } \\
\text { DA2 }\end{array}$ & 18745 & 18015 & 7.83 & 10.7 & 4.50 & 50.1 \\
\hline $0109-264$ & $\begin{array}{l}\text { GD } 691 \\
\text { PHL1003 }\end{array}$ & DA 1 & & & & & 18.80 & $\dagger$ \\
\hline $0134+833$ & $\begin{array}{l}\text { GD } 419 \\
\text { GR 308 } \\
\text { LP2-534 }\end{array}$ & DA 2 & 18730 & & 8.07 & 11.1 & 12.80 & 24.9 \\
\hline 0214+568 & $\begin{array}{l}\text { EG 17 } \\
\text { H PER1166 }\end{array}$ & DA 2 & 21180 & & 7.83 & 10.5 & $\ddagger$ & 43.2 \\
\hline $0227+050$ & $\begin{array}{l}\text { FEIGE } 22 \\
\text { EG } 19\end{array}$ & DA 3 & 19070 & & 7.66 & 10.6 & 17.00 & 27.9 \\
\hline $0410+117$ & $\begin{array}{l}\text { HZ } 2 \\
\text { EG } 31\end{array}$ & DA 3 & 20790 & 19575 & 7.81 & 10.7 & 6.57 & 42.8 \\
\hline $1042-690$ & $\begin{array}{l}\text { BPM } 6502 \\
\text { L101-80 }\end{array}$ & DA 3 & 21380 & & 7.86 & 10.5 & 17.80 & 32.5 \\
\hline $1337+705$ & $\begin{array}{l}\text { G238-44 } \\
\text { EG 102 } \\
\text { LTT 18341 }\end{array}$ & DA 2.5 & 20230 & & 8.05 & 10.7 & 15.60 & 26.2 \\
\hline $2136+828$ & $\begin{array}{l}\text { EG 147 } \\
\text { G261-45 }\end{array}$ & DA 3 & 16940 & 17016 & 7.60 & $\begin{array}{l}10.4 \\
10.9\end{array}$ & 12.10 & 33.4 \\
\hline $2149+021$ & $\begin{array}{l}\text { EG 150 } \\
\text { G93-48 }\end{array}$ & DA 3 & $\begin{array}{l}20547 \\
18250 \\
17653\end{array}$ & & 7.99 & $\begin{array}{l}10.7 \\
11.0\end{array}$ & 14.80 & 25.5 \\
\hline & & WD_A3 & & & & & & \\
\hline $0232+525$ & $\begin{array}{l}\text { GR 314 } \\
\text { G174-5 }\end{array}$ & DA 3 & 17050 & & 8.13 & 11.5 & $\ddagger$ & 28.2 \\
\hline $0310-688$ & $\begin{array}{l}\text { EG 21 } \\
\text { LB3303 } \\
\text { CPD-69 } 177\end{array}$ & DA 3 & 16181 & 15546 & 8.06 & 11.3 & 41.90 & 10.5 \\
\hline $1105-048$ & $\begin{array}{l}\text { EG 76 } \\
\text { G163-50 } \\
\text { LTT } 4099\end{array}$ & DA 3 & $\begin{array}{l}15576 \\
15300 \\
15540 \\
15870\end{array}$ & 16720 & 7.80 & 11.0 & 9.33 & 24.2 \\
\hline
\end{tabular}

Table Notes. ( $\ddagger)$ - no LWP/R spectrum available; $(\dagger)$ - distance not available. 
Table 2. Data on individual late-type DA stars

\begin{tabular}{|c|c|c|c|c|c|c|c|c|}
\hline WD\# & $\begin{array}{l}\text { Other } \\
\text { Names }\end{array}$ & $\begin{array}{l}\text { Spectral } \\
\text { Type }\end{array}$ & $\begin{array}{c}T_{\text {eff }}(\mathrm{K}) \\
\text { (Optical) }\end{array}$ & $\begin{array}{c}T_{\text {eff }}(\mathrm{K}) \\
(\mathrm{UV})\end{array}$ & $\log g$ & $M_{V}$ & $\begin{array}{c}10^{14} \times f_{\lambda}(2646) \\
\left(\operatorname{erg~cm}^{-2} \mathrm{~s}^{-1} \AA^{-1}\right)\end{array}$ & $\begin{array}{l}d_{\odot} \\
(\mathrm{pc})\end{array}$ \\
\hline & & WD_A4 & & & & & & \\
\hline \multirow{2}{*}{$\overline{0352+096}$} & EG 26 & DA 4 & 14420 & 15000 & 8.10 & 11.5 & 2.32 & 40.2 \\
\hline & HZ 4 & & 15100 & 13824 & & & & \\
\hline \multirow{2}{*}{$0406+169$} & EG 29 & DA 4 & 15300 & 16100 & 8.50 & 11.2 & 1.19 & 67.6 \\
\hline & LP414-101 & & 15740 & 15077 & & & & \\
\hline $0954-710$ & $\begin{array}{l}\text { BPM } 6082 \\
\text { L64-27 }\end{array}$ & DA 4 & 13915 & 13876 & 7.72 & 11.1 & 5.48 & 29.9 \\
\hline \multirow{3}{*}{$1327-083$} & G14-58 & DA 4.5 & 14350 & 15520 & 7.82 & 11.3 & 16.60 & 13.8 \\
\hline & $\begin{array}{l}\text { WOLF } 485 \mathrm{~A} \\
\text { EG } 99\end{array}$ & & 12800 & & & 11.9 & & \\
\hline & $\mathrm{BD}-073632 \mathrm{~A}$ & & 14670 & & & & & \\
\hline $1919+145$ & $\begin{array}{l}\text { GD } 219 \\
\text { EG } 201\end{array}$ & DA 4 & 15080 & $\begin{array}{l}15700 \\
14632\end{array}$ & 8.08 & 11.5 & 9.37 & 19.7 \\
\hline \multirow[t]{2}{*}{$2047+372$} & $\begin{array}{l}\text { EG } 261 \\
\text { G210-36 }\end{array}$ & DA 4 & 14660 & $\begin{array}{l}15100 \\
14001\end{array}$ & 8.16 & 11.6 & 9.33 & 20.2 \\
\hline & & WD_A4.5 & & & & & & \\
\hline \multirow[t]{4}{*}{$0133-116$} & ROSS 548 & DA 4 & 11830 & 12400 & 7.97 & 11.6 & $\ddagger$ & 32.5 \\
\hline & EG 10 & & 11990 & 12130 & & & & \\
\hline & G271-106 & & 10000 & & & & & \\
\hline & ZZ Cet & & & & & & & \\
\hline \multirow[t]{2}{*}{$0231-054$} & GD 31 & DA 4 & 12840 & 12910 & & 11.9 & $\ddagger$ & 29.5 \\
\hline & EG 207 & & & & & & & \\
\hline \multirow[t]{2}{*}{$0401+250$} & G8-8 & DA 4 & 12120 & 12227 & 8.20 & 11.9 & 3.34 & 24.0 \\
\hline & EG 28 & & $\begin{array}{l}13248 \\
13500\end{array}$ & & & & & \\
\hline $0713+584$ & GD 294 & DA 3.4 & & 13400 & & & 4.94 & $\dagger$ \\
\hline \multirow{2}{*}{$0858+363$} & GD 99 & DA 4 & 11100 & 12000 & 8.08 & 11.8 & 1.24 & 35.5 \\
\hline & EG 219 & & & & & & & \\
\hline \multirow{3}{*}{$0921+354$} & EG 65 & DA 4 & 11620 & 13150 & 7.97 & 11.7 & $\ddagger$ & 57.5 \\
\hline & G117-B15A & & 12500 & 11890 & & 11.6 & & \\
\hline & & & 11840 & & & & & \\
\hline \multirow[t]{2}{*}{$1425-811$} & L19-2 & DA 4 & 12100 & 12310 & 8.21 & 11.9 & 4.32 & 23.4 \\
\hline & $\begin{array}{l}\text { EG } 110 \\
\text { MY Aps }\end{array}$ & & 12230 & 12640 & & & & \\
\hline \multirow[t]{3}{*}{$1647+591$} & G226-29 & DA 4 & 12120 & 12270 & 8.29 & 11.6 & 13.20 & 13.4 \\
\hline & GR 368 & & 12460 & 12280 & & & & \\
\hline & DN Dra & & & & & & & \\
\hline \multirow[t]{2}{*}{$1855+338$} & EG 127 & DA 4.5 & 10500 & 12060 & & 12.1 & 1.74 & 31.5 \\
\hline & G207-9 & & 12040 & & & & & \\
\hline \multirow{4}{*}{$1935+276$} & G185-32 & DA 4 & 12130 & 11930 & 8.05 & 11.7 & 6.58 & 17.9 \\
\hline & GR 277 & & 11970 & 12370 & & & & \\
\hline & PY Vul & & & & & & & \\
\hline & & WD_A5 & & & & & & \\
\hline \multirow[t]{3}{*}{$1236-495$} & BPM 37093 & DA 4.5 & 12100 & 11530 & 8.81 & 11.9 & 3.35 & 21.5 \\
\hline & LTT 4816 & & 11200 & 11560 & & 12.7 & & \\
\hline & & & 12899 & & & & & \\
\hline \multirow[t]{3}{*}{$1559+369$} & ROSS 808 & DA 4.5 & 11160 & 11180 & 8.04 & 11.9 & 1.58 & 31.0 \\
\hline & G180-23 & & 10880 & 11560 & & & & \\
\hline & $\begin{array}{l}\text { EG } 115 \\
\text { TY CrB }\end{array}$ & & 11200 & & & & & \\
\hline \multirow{3}{*}{$2326+049$} & G29-38 & DA 4 & 11820 & 11650 & 8.14 & 11.9 & 5.93 & 16.8 \\
\hline & EG 159 & & 11900 & & & & & \\
\hline & ZZ Psc & & & & & & & \\
\hline
\end{tabular}

Table Notes. ( $\ddagger)$ - no LWP/R spectrum available; $(\dagger)$ - distance not available.

designations following MS87; (3) optical spectral type from MS87; (4) optical effective temperature; (5) ultraviolet (UV) effective temperature; (6) surface gravity; (7) visual absolute magnitude from MS87; (8) observed monochromatic $f_{\lambda}$ flux at $\lambda 2646 \AA$; and finally (9) distance from the Sun. The sources for Cols. (4)-(6) and (9) are: Shipman (1979), Bergeron et al. (1992), Vennes (1992), Koester \& Allard (1993), Kepler et al. (1995), Kepler \& Nelan (1993), Bergeron et al. (1995) and Bragaglia et al. (1995) for DA's; Koester et al. (1981), Liebert et al. (1986), Oke et al. (1984), Wegner \& Nelan (1987) and Thejll et al. (1991) for DB's; Wesemael et al. (1985), Liebert et al. (1989) and Werner et al. (1991) for DO's; for white dwarfs in general, we used information from Green (1980), Fleming et al. (1986), Liebert et al. (1988), Thejll et al. (1991), Werner \& Heber et al. (1991), Bradley et al. (1993), Motch et al. (1993) and Wesemael et al. (1993). Stellar fluxes in Col. (8) were measured in our average spectra for individual white dwarfs. An asterisk in Col. (9) of Tables 3 and 4 indicates that the distance was not available in the literature above. In such cases, we assumed the average $M_{V}$ of the corresponding group (see Table 5 in Sect. 3) to estimate the distance modulus. For a few stars, the apparent 
Table 3. Data on individual DO stars

\begin{tabular}{|c|c|c|c|c|c|c|c|c|}
\hline WD\# & $\begin{array}{l}\text { Other } \\
\text { Names }\end{array}$ & $\begin{array}{l}\text { Spectral } \\
\text { Type } \\
\end{array}$ & $\begin{array}{c}T_{\text {eff }}(\mathrm{K}) \\
\text { (Optical) }\end{array}$ & $\begin{array}{c}T_{\text {eff }}(\mathrm{K}) \\
(\mathrm{UV})\end{array}$ & $\log g$ & $M_{V}$ & $\begin{array}{c}10^{14} \times f_{\lambda}(2646) \\
\left(\mathrm{erg} \mathrm{cm}^{-2} \mathrm{~s}^{-1} \AA^{-1}\right)\end{array}$ & $\begin{array}{c}d_{\odot} \\
(\mathrm{pc})\end{array}$ \\
\hline & & DO 2 & & & & & & \\
\hline$\overline{0108+100}$ & $\begin{array}{l}\text { GR 900 } \\
\text { PG 0108+100 }\end{array}$ & DO 1 & 80000 & & $\geq 7.0$ & 7.8 & 2.69 & $\bar{\dagger}$ \\
\hline $0109+111$ & $\begin{array}{l}\text { GR } 901 \\
\text { PG } 0109+111\end{array}$ & DO 1 & 80000 & & $\geq 7.0$ & 7.8 & 3.24 & $\dagger$ \\
\hline $1133+489$ & PG $1133+489$ & DO 1 & 47500 & & $\geq 7.0$ & 9.0 & 0.74 & $\dagger$ \\
\hline $1211+332$ & $\begin{array}{l}\text { EG } 295 \\
\text { HZ } 21\end{array}$ & DA 3 & 50000 & & $\geq 7.0$ & 8.8 & 6.79 & $\dagger$ \\
\hline $1707+427$ & $\begin{array}{l}\text { V } 817 \text { Her } \\
\text { PG } 1707+427\end{array}$ & DO & 100000 & & $\geq 7.0$ & & 0.38 & $461^{*}$ \\
\hline $2131+066$ & $\begin{array}{l}\text { IR Peg } \\
\text { PG } 2131+066\end{array}$ & DO & 85000 & & 7.5 & & 1.36 & 470 \\
\hline & & DO 1 & & & & & & \\
\hline$\overline{1034+001}$ & PG $1034+001$ & DOZ 1 & 80000 & & $\geq 7.0$ & 7.8 & 28.20 & $\dagger$ \\
\hline $1151-029$ & PG 1151-029 & DOZ 1 & & & & & 2.02 & $\dagger$ \\
\hline $1159-035$ & GW Vir & DOZ 1 & 140000 & & $\geq 7.0$ & & 7.01 & $210^{*}$ \\
\hline $1253+378$ & $\begin{array}{l}\text { EG } 93 \\
\text { HZ } 34\end{array}$ & DO & 60000 & & $\sim 7.0$ & & 2.53 & $\dagger$ \\
\hline $1424+534$ & PG $1424+534$ & $\mathrm{DOZ} 1$ & 100000 & & 7.0 & & 2.40 & $393^{*}$ \\
\hline $1520+525$ & PG $1520+525$ & DOZ 1 & 140000 & & 7.0 & & 3.41 & $287^{*}$ \\
\hline $1634-573$ & HD 149499B & DOZ 1 & & & & & 127.0 & $\dagger$ \\
\hline $1821+643$ & $\begin{array}{l}\text { DS Dra } \\
\text { K1-16 }\end{array}$ & & & & & & 5.79 & $230^{*}$ \\
\hline
\end{tabular}

Table Notes. Data for PG 2131+066 are from Kawaler et al. (1995); $(\dagger)$ - distance not available.

visual magnitude was not available and consequently they lack distance estimates, as indicated in Tables 1-4.

To obtain the final spectrum for each object we first averaged individual spectra working separately in the short (SWP) and long (LWP and LWR) wavelength ranges. A few spectra were eliminated at this stage because they presented problems such as instrumental defects, discordant continuum distribution and/or spectral features. During this treatment of individual objects, the short and long wavelength domains were processed separately. The weights in the averages were given according to the square of the $(S / N)$. This procedure allowed us to obtain the highest possible $(S / N)$ spectra. Recently, this method has been applied to integrated spectra of star clusters in the IUE library providing new information from the derived templates (Bonatto et al. 1995). Since all the objects are nearby, and in no case was the $\lambda 2175 \AA$ dust absorption feature evident, no reddening correction was applied to the spectra. The spectra have been corrected of the IUE réseau marks at $\lambda 1790 \AA$ and $\lambda 3056 \AA$.

\section{The templates and their properties}

We used the optical spectral types for individual stars (Col. (3) in Tables 1-4) as a guide to create the groups, but the fundamental criterion was the similarity of the IUE spectra. Each average stellar spectrum contributed to its group formation with a weight proportional to the $(S / N)$. The resulting DA groups are shown in Fig. 1, and those for DO's and DB's in Fig. 2. Notice the remarkable slope range, primarily a temperature effect. Differences in spectral features are also apparent (Sect.4).

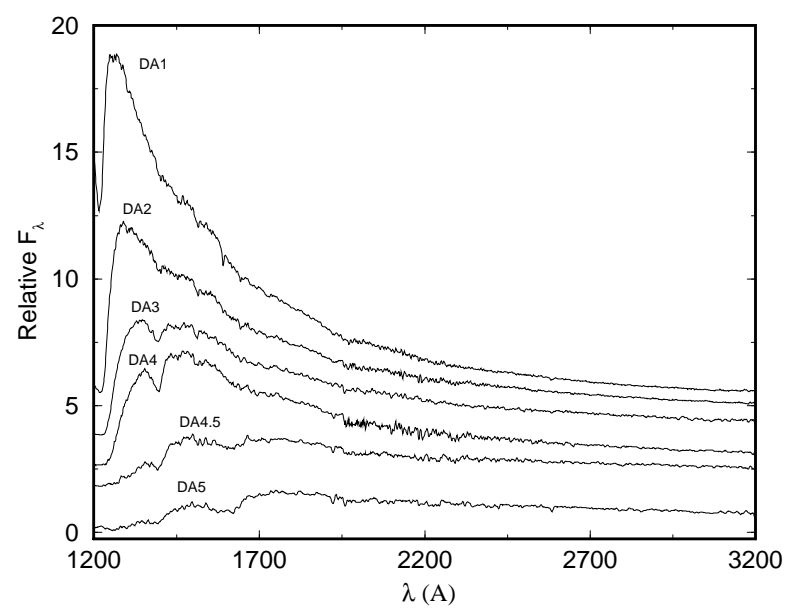

Fig. 1. The resulting templates for DA stars. Notice the Ly $\alpha$ wing and the wide features at $\lambda 1400 \AA$ and $\lambda 1600 \AA$. The spectra are normalised at $\lambda 2646 \AA$ and constants have been added to them, except for the bottom one

We present in Table 5 average properties for each group, by Cols. (1) group designation; (2) and (3) effective temperatures from optical and ultraviolet studies, respectively; (4) the adopted effective temperatures, which are averages of Cols. (2) and (3); (5) surface gravity $(\log g)$; (6) and (7) absolute visual magnitudes $\left(M_{V}\right)$ respectively derived averaging $M_{V}$ 's for individual stars from MS87, and theoretically predicted values using the adopted temperatures and surface gravities for the groups (Cols. (4) and (5)), and the models used in Bergeron et al. (1995); (8) luminosity in solar units $\left(\log \left(L / L_{\odot}\right)\right)$; and finally (9) the intrinsic monochromatic flux $F_{\lambda}$ at $\lambda 2646 \AA$, at the white 
Table 4. Data on individual DB stars

\begin{tabular}{|c|c|c|c|c|c|c|c|c|}
\hline WD\# & $\begin{array}{l}\text { Other } \\
\text { Names }\end{array}$ & $\begin{array}{l}\text { Spectral } \\
\text { Type }\end{array}$ & $\begin{array}{c}T_{\text {eff }}(\mathrm{K}) \\
\text { (Optical) }\end{array}$ & $\begin{array}{c}T_{\text {eff }}(\mathrm{K}) \\
\text { (UV) }\end{array}$ & $\log g$ & $M_{V}$ & $\begin{array}{c}10^{14} \times f_{\lambda}(2646) \\
\left(\operatorname{erg~cm}^{-2} \mathrm{~s}^{-1} \AA^{-1}\right)\end{array}$ & $\begin{array}{l}d_{\odot} \\
(\mathrm{pc})\end{array}$ \\
\hline & & & & & & & & \\
\hline$\overline{0111+104}$ & GR 409 & DB 2.5 & 28900 & 30000 & 8.07 & 11.0 & 2.12 & 77.3 \\
\hline $0853+163$ & $\begin{array}{l}\text { PG } 0112+104 \\
\text { PG } 0853+158 \\
\text { GR } 904\end{array}$ & DB 2.5 & & $\begin{array}{l}29000 \\
22000\end{array}$ & & & 1.11 & $\dagger$ \\
\hline $1115+158$ & $\begin{array}{l}\text { PG } 1115+158 \\
\text { DT Leo }\end{array}$ & DB 2 & 22500 & $\begin{array}{l}26000 \\
25000\end{array}$ & & & 0.42 & $\dagger$ \\
\hline $1149-133$ & PG 1149-133 & DB 2 & & $\begin{array}{l}21000 \\
20000\end{array}$ & & & 0.71 & $\dagger$ \\
\hline $1326-037$ & PG 1326-034 & DB 2 & & $\begin{array}{l}22000 \\
21000\end{array}$ & & & 1.16 & $\dagger$ \\
\hline $1346+082$ & $\begin{array}{l}\text { PG } 1346+082 \\
\text { CR Boo }\end{array}$ & DB & & & & & 1.72 & $\dagger$ \\
\hline $1351+489$ & $\begin{array}{l}\text { PG } 1351+489 \\
\text { EM UMa }\end{array}$ & DB 2 & 22000 & $\begin{array}{l}25000 \\
24000\end{array}$ & & & 0.61 & $125.9^{*}$ \\
\hline $1456+103$ & $\begin{array}{l}\text { PG } 1456+103 \\
\text { CW Boo }\end{array}$ & DB 3 & 22500 & $\begin{array}{l}24000 \\
23000\end{array}$ & & & 0.90 & $100.5^{*}$ \\
\hline $1645+325$ & $\begin{array}{l}\text { V777 Her } \\
\text { GD } 358\end{array}$ & DB 2 & 24000 & $\begin{array}{l}28000 \\
27000\end{array}$ & 7.84 & 10.8 & 9.95 & 43.6 \\
\hline $1654+160$ & $\begin{array}{l}\text { V824 Her } \\
\text { PG } 1654+160\end{array}$ & DB 2 & 28500 & $\begin{array}{l}26000 \\
25000\end{array}$ & & & 0.65 & $113.2^{*}$ \\
\hline$\overline{0100-060}$ & $\begin{array}{l}\text { G270-124 } \\
\text { GR 513 } \\
\text { BPM 70524 } \\
\text { PHL 962 }\end{array}$ & $\begin{array}{l}\text { WD_B3 } \\
\text { DB 3 }\end{array}$ & $\begin{array}{l}19000 \\
23000 \\
17000\end{array}$ & $\begin{array}{l}25000 \\
22000\end{array}$ & & 10.9 & 5.94 & 37.3 \\
\hline $0308-566$ & $\begin{array}{l}\text { BPM } 17088 \\
\text { L175-34 }\end{array}$ & DB 3 & 18000 & $\begin{array}{l}21500 \\
23000\end{array}$ & & 11.3 & 5.48 & 35.0 \\
\hline $0418-539$ & BPM 17731 & DB 3 & 16900 & $\begin{array}{l}18000 \\
20000\end{array}$ & & 11.4 & 1.91 & 61.1 \\
\hline & & WD_B3.5 & & & & & & \\
\hline$\overline{0017+136}$ & $\begin{array}{l}\text { EG 3 } \\
\text { FEIGE } 4\end{array}$ & DB 3 & $\begin{array}{l}13100 \\
17540\end{array}$ & & 8.01 & 11.3 & 1.60 & 63.1 \\
\hline $0840+262$ & $\begin{array}{l}\text { GR } 291 \\
\text { TON } 10\end{array}$ & DB 3 & $\begin{array}{l}16500 \\
17310\end{array}$ & 16000 & & 11.4 & 2.67 & 48.5 \\
\hline $\begin{array}{l}0948+013 \\
1445+152\end{array}$ & $\begin{array}{l}\text { PG } 0948+013 \\
\text { PG } 1445+152\end{array}$ & $\begin{array}{l}\mathrm{DB} 2 \\
\mathrm{DB} 2\end{array}$ & & $\begin{array}{l}18000 \\
23000 \\
19000\end{array}$ & & & $\begin{array}{c}\ddagger \\
1.00\end{array}$ & $\begin{array}{l}\dagger \\
\dagger\end{array}$ \\
\hline $1940+374$ & $\begin{array}{l}\text { EG 133 } \\
\text { L1573-31 }\end{array}$ & DB 3 & $\begin{array}{l}15820 \\
16000\end{array}$ & 17000 & 7.71 & 11.5 & 3.31 & 39.8 \\
\hline $2224-344$ & $\begin{array}{l}\text { EG } 153 \\
\text { LTT } 9031\end{array}$ & DB 2 & $\begin{array}{l}15200 \\
19000\end{array}$ & 20000 & & & 3.74 & $41.9^{*}$ \\
\hline & & WD_B4 & & & & & & \\
\hline$\overline{0300-013}$ & $\begin{array}{l}\text { GD 40 } \\
\text { GR 384 }\end{array}$ & DBZ 4 & $\begin{array}{l}18000 \\
13730\end{array}$ & & 7.85 & 11.4 & 0.87 & 67.3 \\
\hline $0615-591$ & $\begin{array}{l}\text { BPM } 18164 \\
\text { L182-61 }\end{array}$ & DB 4.5 & 15300 & 14600 & & 11.4 & 4.89 & 34.2 \\
\hline $1333+487$ & $\begin{array}{l}\text { GD } 325 \\
\text { GR } 359\end{array}$ & DB & & & & & 4.69 & $33.0^{*}$ \\
\hline $\begin{array}{l}1411+218 \\
1459+821\end{array}$ & $\begin{array}{l}\text { PG } 1411+218 \\
\text { GR } 393 \\
\text { G256-18 } \\
\text { LP8-157 }\end{array}$ & $\begin{array}{l}\text { DB } 4 \\
\text { DB } 4\end{array}$ & 15030 & 14000 & 7.52 & 11.5 & $\begin{array}{l}2.97 \\
2.29\end{array}$ & $\begin{array}{c}\dagger \\
46.3\end{array}$ \\
\hline$\overline{0000-170}$ & $\begin{array}{l}\text { G226-32 } \\
\text { LTT } 11\end{array}$ & $\begin{array}{l}\text { WD_B5 } \\
\text { DB 4 }\end{array}$ & 12110 & 11000 & 7.52 & 11.7 & 1.99 & 50.4 \\
\hline $0002+729$ & $\begin{array}{l}\text { GD } 408 \\
\text { GR } 305\end{array}$ & DB 4 & 13310 & 13000 & 7.69 & 11.4 & 2.88 & 38.2 \\
\hline $1129+004$ & $\begin{array}{l}\text { BD 004234 } \\
\text { L1002-16 }\end{array}$ & DA & & & & & 2.35 & $\dagger$ \\
\hline $2147+280$ & $\begin{array}{l}\text { GR 583 } \\
\text { G187-27 }\end{array}$ & DB 4.5 & 14000 & & & & $\ddagger$ & $42.5^{*}$ \\
\hline
\end{tabular}

Table Notes. ( $\ddagger)$ - no LWP/R spectrum available; $(\dagger)$ - distance not available. 


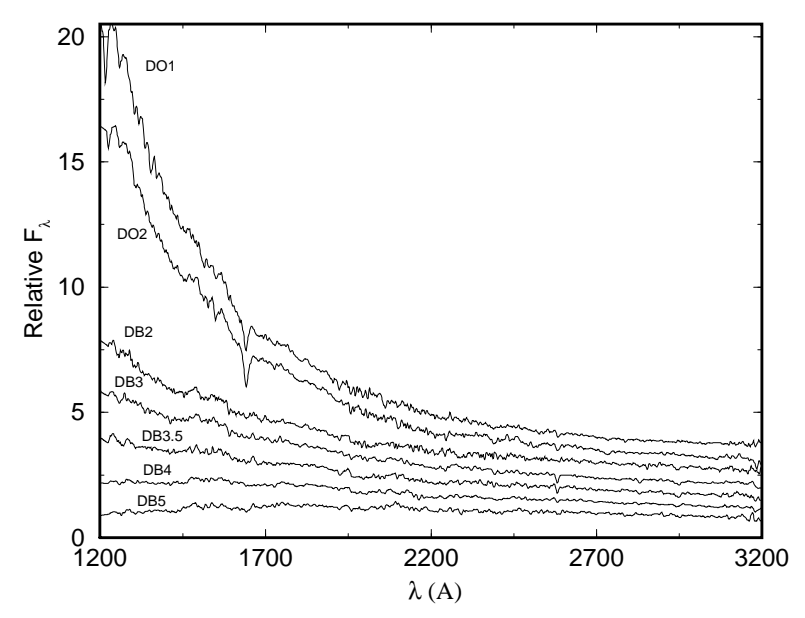

Fig. 2. The resulting templates for DO and DB stars. Notice the strong $\mathrm{He}_{\lambda 1640}$ in the DO templates, and the excess flux around $1430-1600 \AA$ in the DB ones. The spectra are normalised at $\lambda 2646 \AA$ and constants have been added to them, except for the bottom one

dwarf surface. The effective temperatures for each group were obtained by first averaging the available temperatures for each individual star and then averaging among stars in the group (Tables 1-4). Optical and UV determinations were treated separately. A similar approach was applied to derive the $\log g$ and $M_{V}$ values. The intrinsic flux in Col. (9) is the average of those of the individual stars in each group, and was calculated with the observed flux in Col. (8) and distance $(d)$ in Col. (9) in Tables 14, using $F_{\lambda}(2646)=4 \pi d^{2} \times f_{\lambda}(2646)$, and then dividing this value by the typical white dwarf radius (Koester \& Schönberner 1986) for each group.

A comparison of the optical and ultraviolet temperatures, shows that the latter are typically $\approx 600 \mathrm{~K}$ higher for DA 3 to DA 4.5, whereas for DA 5, the optical one is somewhat higher. For DB's, UV temperatures are typically $\approx 2000 \mathrm{~K}$ higher for the range DB 2 to DB 3.5, whereas for DB 4 and DB 5, the optical ones are typically $\approx 900 \mathrm{~K}$ higher.

A comparison of the $M_{V}$ values for the groups in Cols. (6) and (7), shows that the mean differences are 0.10 and 0.25 respectively for DA and DB groups, in the sense that the theoretically predicted values are systematically brighter (except DA 5) than those observationally determined.

The standard deviations for temperatures in Cols. (2) and (3) of Table 5 in principle should reflect the internal dispersion of $T_{\text {eff }}$ among the different stars making up the group. However, as can be seen in the tables for individual stars, the spread in temperature determinations in the optical or UV for a given star can be of the same order. Luminosities for DA and DB groups were calculated taking into account the models of Bergeron et al. (1995), using as input parameters the average $T_{\text {eff }}$ and $\log g$ for each group
(Table 5). For the group WD_B3, we adopted $\log g=7.9$, which is the interpolated value from the DB groups. Luminosities for the DO groups were obtained from the models of Koester \& Schönberner (1986).

\section{Measurements and discussion}

As shown in Figs. 1 and 2, the UV spectra of white dwarfs present few prominent spectral features. The main difference between DA's and DB's is the presence of the Ly $\alpha$ wing in the spectra of the former. Other characteristics appear in DA 3 to DA 5 stars, which are the wide absorption features centred at $\approx \lambda 1600 \AA$ and $\lambda 1400 \AA$, which Koester et al. (1985) and Nelan \& Wegner (1985) identified as, respectively, a resonance broadening of Ly $\alpha$ by the hydrogen quasi molecule, and a satellite line to $\operatorname{Ly} \alpha$ arising from the hydrogen ion quasi molecule. Nelan \& Wegner (1985) pointed out that the $\lambda 1400 \AA$ feature appears for $T_{\text {eff }}<19000 \mathrm{~K}$, and the $\lambda 1600 \AA$ for $T_{\text {eff }}<13500 \mathrm{~K}$. This is confirmed in our average spectra (Fig.1) and properties (Table 5). In the DO's, a prominent line of He $\mathrm{II}_{\lambda 1640}$ is present (Fig. 2). The most conspicuous feature in DB stars is the flux excess around $1430-1600 \AA$ (Fig. 2). The origin of this feature is not clear, nor whether it arises from emission, or is caused by side absorptions. It also occurs in sdB stars with $T_{\text {eff }} \approx 30000 \mathrm{~K}$, for which we also built templates from IUE spectra. This piece of evidence suggests that helium and/or other elements in common among these stars, may be responsible for the observed feature. It would be important to compute model spectra that can reproduce such features.

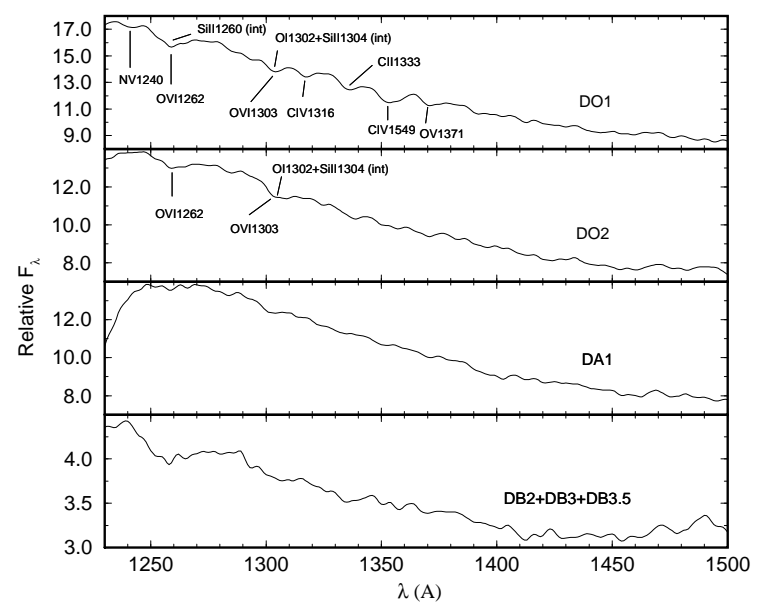

Fig. 3. Blow-up of the region 1230-1500 A. Intrinsic absorption features are marked together with some possible interstellar absorptions

In Figs. 3-5 we present blow-ups of different spectral regions for particular templates in order to show in more detail weak absorption lines. In the DO stars, the $\mathrm{He}_{\lambda 1640}$ absorption line is prominent (Fig. 4), but some weaker lines are also evident, which arise from high ionization 
Table 5. Properties of the white dwarf groups

\begin{tabular}{|c|c|c|c|c|c|c|c|c|}
\hline Group & $\begin{array}{r}T_{\text {eff }}(\mathrm{K}) \\
(\text { Optical }) \\
\end{array}$ & $\begin{array}{l}T_{\text {eff }}(\mathrm{K}) \\
(\mathrm{UV})\end{array}$ & $\begin{array}{r}T_{\text {eff }}(\mathrm{K}) \\
\text { (adopted) } \\
\end{array}$ & $\log g$ & $\begin{array}{c}\mathrm{M}_{V} \\
(\mathrm{MS} 87)\end{array}$ & $\begin{array}{c}M_{V} \\
\text { (theor.) }\end{array}$ & $\log \left(L / L_{\odot}\right)$ & $\begin{array}{c}10^{-9} \times F_{\lambda}(2646) \\
\left(\mathrm{erg} \mathrm{cm}^{-2} \mathrm{~s}^{-1} \AA^{-1}\right)\end{array}$ \\
\hline$\overline{\text { WD_A1 }}$ & $35862 \pm 9516$ & $39967 \pm 10856$ & 37900 & $8.05 \pm 0.41$ & 10.07 & 9.58 & -0.53 & $5.51 \pm 4.45$ \\
\hline WD_A2 & $19446 \pm 1534$ & $18202 \pm 1290$ & 18800 & $7.86 \pm 0.16$ & 10.69 & 10.64 & -1.57 & $1.48 \pm 0.39$ \\
\hline WD_A3 & $16268 \pm 743$ & $16133 \pm 830$ & 16200 & $8.00 \pm 0.17$ & 11.26 & 11.10 & -1.97 & $0.64 \pm 0.75$ \\
\hline WD_A4 & $14646 \pm \quad 632$ & $14852 \pm 682$ & 14750 & $8.06 \pm 0.28$ & 11.35 & 11.35 & -2.16 & $0.52 \pm 0.10$ \\
\hline WD_A45 & $11992 \pm 671$ & $12428 \pm 431$ & 12200 & $8.07 \pm 0.14$ & 11.76 & 11.70 & -2.56 & $0.26 \pm 0.04$ \\
\hline WD_A5 & $11669 \pm 520$ & $11521 \pm 141$ & 11600 & $8.33 \pm 0.42$ & 11.93 & 12.21 & -2.79 & $0.20 \pm 0.01$ \\
\hline DO 1 & $104000 \pm 35777$ & - & 104000 & $\geq 7.0$ & 8.23 & - & 1.50 & $11.3 \pm 8.74$ \\
\hline DO 2 & $73750 \pm 20721$ & - & 74000 & $\geq 7.0$ & 8.37 & - & 0.81 & $26.9 \pm 3.22$ \\
\hline WD_B2 & $23880 \pm 2945$ & $24750 \pm 2964$ & 24300 & $7.96 \pm 0.16$ & 10.88 & 10.40 & -1.28 & $1.49 \pm 0.52$ \\
\hline WD_B3 & $18189 \pm 1393$ & $22000 \pm 2598$ & 20100 & 7.90 & 11.21 & 10.50 & -1.62 & $0.98 \pm 0.10$ \\
\hline WD_B35 & $16309 \pm 840$ & $17875 \pm 1750$ & 17100 & $7.86 \pm 0.21$ & 11.39 & 10.76 & -1.84 & $0.81 \pm 0.07$ \\
\hline WD_B4 & $14687 \pm 839$ & $14300 \pm \quad 424$ & 14350 & $7.68 \pm 0.23$ & 11.42 & 10.93 & -2.06 & $0.66 \pm 0.09$ \\
\hline WD_B5 & $13140 \pm 956$ & $12000 \pm 1414$ & 12550 & $7.60 \pm 0.12$ & 11.54 & 11.15 & -2.25 & $0.61 \pm 0.07$ \\
\hline
\end{tabular}

species (Fig. 3) such as OVI and OV (Werner 1991); this is expected for temperatures in excess of $70000 \mathrm{~K}$ (Table 5). Some interstellar absorptions may be present too, as indicated in the figures. In the LWP/R domain (Fig. 5), He II Paschen lines are present in DO stars, while in DB's, strong HeI lines occur.

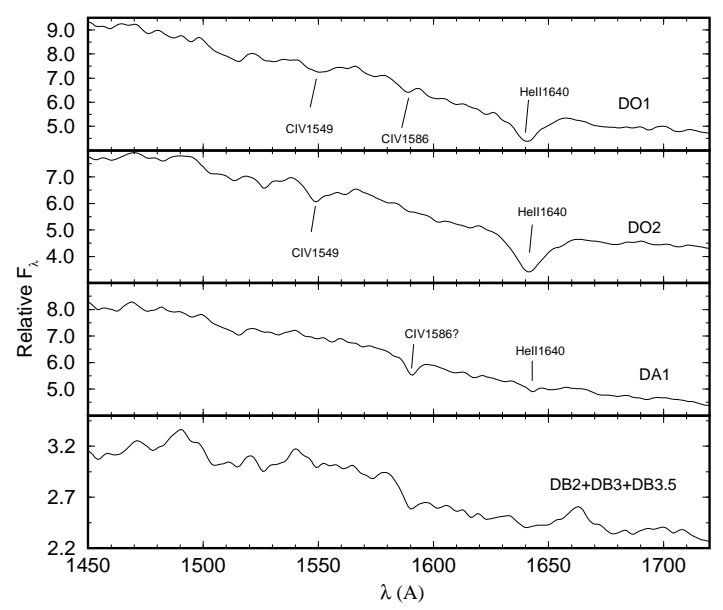

Fig. 4. Same as Fig. 3 for the region $1450-1720 \AA$

In Table 6 we show equivalent width measurements of the prominent features present in the templates. Since the He $\mathrm{II}_{\lambda 1640}$ feature in DO's presents a conspicuous core and wing structure, we adopted continuum at $\lambda 1573 \AA$ and $\lambda 1747 \AA$, while the spectral window for the core only, and core plus wings, are indicated in the table. We measured the excess flux at $1430-1600 \AA$ in DB stars as an emission feature, by adopting adjacent continuum points. For the $\lambda 1400 \AA$ and $\lambda 1600 \AA$ absorption features in DA stars, the continuum points correspond to the window edges, as indicated in the table.

He $\mathrm{II}_{\lambda 1640}$ is $\approx 30 \%$ stronger in the DO 2 template than in the DO 1 one. The excess at $1430-1600 \AA$ in DB stars becomes stronger with decreasing temperature, except for the coolest group, DB 5. The $\lambda 1400 \AA$ feature in
DA stars increases with decreasing temperature, and is still detectable in the DA 2 template. The $\lambda 1600 \AA$ feature also increases with decreasing temperature, but it is essentially absent in DA 3 or hotter groups.

We plot in Fig. 6 continuum ratios in the UV as a function of $\log \left(T_{\text {eff }}\right)$ for each group. Notice that despite the internal dispersion and/or errors in the $T_{\text {eff }}$ values (as discussed in Sect. 3), the groups are well distinguished within each white dwarf class. Finally, in Table 7 we present continuum measurements relative to that at $\lambda 2646 \AA$. This spectral distribution, coupled to the absolute monochromatic fluxes at $\lambda 2646 \AA$ (Table 5 ), can be used to scale the present white dwarf templates with respect to other stellar types, in view of stellar population syntheses.

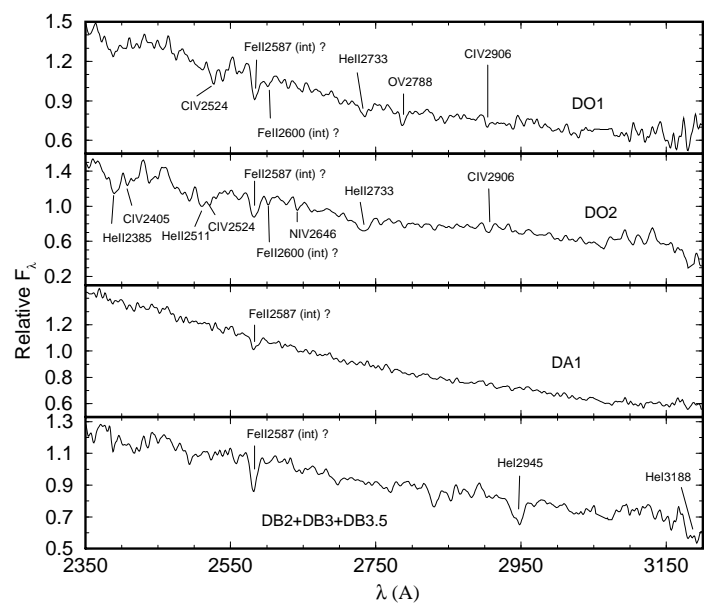

Fig. 5. Same as Fig. 3 for the region $2350-3170 \AA$

\section{Concluding remarks}

We built high $(S / N)$ spectral templates for different classes of white dwarfs, using the IUE database. We obtained 6 groups for DA, 5 for DB and 2 for DO stars, for which we also derived average properties. We emphasise 
Table 6. Equivalent widths of main features

\begin{tabular}{lccccc}
\hline \hline Group & $\mathrm{HeII}_{\lambda 1640}$ & $\mathrm{HeII}_{\lambda 1640}$ & Excess & $\lambda 1400 \AA$ & $\lambda 1600 \AA$ \\
& $1625-1655 \AA$ & $1573-1747 \AA$ & $1430-1610 \AA$ & $1352-1430 \AA$ & $1493-1668 \AA$ \\
\hline DO 1 & $5.6 \pm 0.5$ & $15.3 \pm 2.5$ & - & - & - \\
DO 2 & $7.8 \pm 0.5$ & $19.1 \pm 2.5$ & - & - & - \\
WD_B2 & - & - & $-12.0 \pm 1.0$ & - & - \\
WD_B3 & - & - & $-14.0 \pm 1.0$ & - & - \\
WD_B3.5 & - & - & $-16.0 \pm 1.0$ & - & - \\
WD_B4 & - & - & $-20.7 \pm 1.0$ & - & - \\
WD_B5 & - & - & $-17.0 \pm 2.0$ & - & $2.5 \pm 2.5$ \\
WD_A2 & - & - & - & $1.8 \pm 0.5$ & $2.5 \pm 2.0$ \\
WD_A3 & - & - & - & $6.5 \pm 0.3$ & $5.9 \pm 1.5$ \\
WD_A4 & - & - & - & $9.3 \pm 0.4$ & $16.9 \pm 2.5$ \\
WD_A4.5 & - & - & - & $18.4 \pm 0.6$ & $25.8 \pm 4.0$ \\
WD_A5 & - & - & - & $33.9 \pm 1.5$ & \\
\hline
\end{tabular}

Table Notes. Equivalent widths are in $\AA$; negative values indicate emission.

Table 7. Continuum measurements $-C_{\lambda} / C_{2646}$

\begin{tabular}{|c|c|c|c|c|c|c|c|c|c|c|c|c|c|}
\hline$\lambda(\AA)$ & 1242 & 1282 & 1348 & 1490 & 1587 & 1768 & 1830 & 2079 & 2123 & 2258 & 2466 & 2959 & $\overline{3122}$ \\
\hline WD_A1 & $14.09^{*}$ & 13.59 & 10.90 & 7.87 & 6.24 & 4.10 & 3.69 & 2.28 & 2.11 & 1.61 & 1.28 & 0.71 & 0.58 \\
\hline WD_A2 & $8.09^{*}$ & 7.69 & 6.92 & 5.49 & 4.56 & 3.09 & 2.83 & 1.86 & 1.75 & 1.50 & 1.22 & 0.73 & 0.63 \\
\hline WD_A3 & $4.73^{*}$ & 4.67 & 4.62 & 4.39 & 3.80 & 2.66 & 2.44 & 1.76 & 1.66 & 1.39 & 1.14 & 0.78 & 0.70 \\
\hline WD_A4 & $4.57^{*}$ & $4.57^{*}$ & $4.58^{*}$ & 4.57 & 3.87 & 2.82 & 2.61 & 1.72 & 1.64 & 1.41 & 1.17 & 0.77 & 0.69 \\
\hline WD_A4.5 & $1.74^{*}$ & $1.75^{*}$ & $1.77^{*}$ & 1.99 & 1.96 & 1.94 & 1.84 & 1.36 & 1.30 & 1.19 & 1.12 & 0.90 & 0.85 \\
\hline WD_A5 & $0.58^{*}$ & $0.66^{*}$ & $0.80^{*}$ & 1.10 & 1.31 & 1.63 & 1.57 & 1.26 & 1.23 & 1.19 & 1.07 & 0.86 & 0.80 \\
\hline DO 1 & 17.25 & 15.69 & 12.50 & 8.75 & 6.83 & 4.51 & 3.96 & 2.42 & 2.16 & 1.66 & 1.26 & 0.72 & 0.63 \\
\hline DO 2 & 13.82 & 13.03 & 10.25 & 7.57 & 6.00 & 4.09 & 3.61 & 2.12 & 1.89 & 1.52 & 1.25 & 0.70 & 0.58 \\
\hline WD_B2 & 5.61 & 5.24 & 4.43 & $3.73^{\dagger} / 3.49^{\ddagger}$ & $3.23^{\dagger} / 3.00^{\ddagger}$ & 2.47 & 2.30 & 1.61 & 1.56 & 1.33 & 1.13 & 0.75 & 0.65 \\
\hline WD_B3 & 4.34 & 4.05 & 3.68 & $3.34^{\dagger} / 3.01^{\ddagger}$ & $2.81^{\dagger} / 2.68^{\ddagger}$ & 2.34 & 2.18 & 1.69 & 1.60 & 1.40 & 1.15 & 0.79 & 0.73 \\
\hline WD_B3.5 & 3.00 & 2.87 & 2.60 & $2.53^{\dagger} / 2.27^{\ddagger}$ & $2.20^{\dagger} / 2.11^{\ddagger}$ & 1.95 & 1.90 & 1.47 & 1.36 & 1.20 & 1.06 & 0.76 & 0.73 \\
\hline WD_B4 & 1.72 & 1.76 & 1.69 & $1.85^{\dagger} / 1.65^{\ddagger}$ & $1.77^{\dagger} / 1.62^{\ddagger}$ & 1.64 & 1.61 & 1.35 & 1.31 & 1.16 & 1.07 & 0.81 & 0.74 \\
\hline WD_B5 & 1.00 & 1.06 & 1.07 & $1.32^{\dagger} / 1.10^{\ddagger}$ & $1.17^{\dagger} / 1.16^{\ddagger}$ & 1.33 & 1.28 & 1.25 & 1.18 & 1.11 & 1.07 & 0.88 & 0.82 \\
\hline
\end{tabular}

Table Notes. $\left(^{*}\right)$ - extrapolated because of Ly $\alpha$ absorption wing; $(\dagger)$ - considering the $1430-1600 \AA$ feature as emission; $(\ddagger)$ - considering the 1430-1600 A feature as absorption. Errors are typically \pm 0.02 , except in the extrapolated zones.

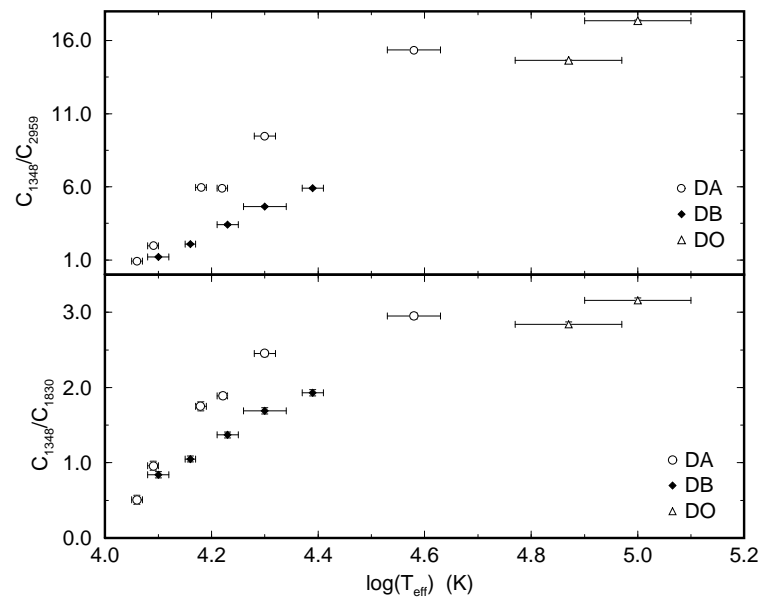

Fig. 6. Continuum ratios $C_{1348} / C_{1830}$ and $C_{1348} / C_{2959}$ plotted as functions of $T_{\text {eff }}$

the most conspicuous spectral features in these templates which might be useful discriminators in the study of composite stellar populations. The DA templates are characterised by a strong Ly $\alpha$ absorption and, for some tem- plates, by wide absorptions around $\lambda 1400 \AA$ and $\lambda 1600 \AA$; the DO spectra present strong $\mathrm{He} \mathrm{II}_{\lambda 1640}$ absorptions; and the DB templates are characterised by an excess flux around 1430-1600 $\AA$ and by the presence of some He I lines. The DO 1, DO 2 and DA 1 templates present very steep slopes (in $F_{\lambda}$ units) in the UV. This spectral library for the latest stages of stellar evolution will be a valuable tool in stellar population syntheses of galaxies and star clusters.

Acknowledgements. We thank Dr. D. Koester for interesting remarks. We acknowledge the Brazilian institutions CNPq and FINEP for partially supporting this work.

\section{References}

Bergeron P., Saffer R.A., Liebert J., 1992, ApJ 394, 228

Bergeron P., Wesemael F., Lamontagne R., Fontaine G., Saffer R.A., Allard N.F., 1995, ApJ 449, 258

Bica E., Bonatto C., Pastoriza M.G., Alloin D., 1996, A\&A (in press)

Bonatto C., Bica E., Alloin D., 1995, A\&AS 112, 71

Bradley P.A., 1993, in The Second WET Workshop. In: Meistas E., Solheim J.-E. (eds.), Baltic Astron. 2, 559 
Bragaglia A., Renzini A., Bergeron P., 1995, ApJ 443, 735

Courvoisier T. J.-L., Paltani S., 1992, IUE-ULDA Access Guide No.4, ESA Publications Division, Noordwijk, The Netherlands

Fleming T.A., Liebert J., Green R.F., 1986, ApJ 308, 176

Green R.F., 1980, ApJ 238, 685

Kawaler S.D., et al., 1995, ApJ 450, 350

Kepler S.O., Giovannini O., Kanaan A., Wood M.A., Claver C.F., 1995, Baltic Astron. (in press)

Kepler S.O., Nelan E.P., 1993, AJ 105, 608

Koester D., Schulz H., Wegner G., 1981, A\&A 102, 331

Koester D., Weidemann V., Zeidler-K.T. E.-M., Vauclair G., 1985, A\&A 142, L5

Koester D., Schönberner D., 1986, A\&A 154, 125

Koester D., Allard N., 1993, in White Dwarfs: Advances in Observation and Theory. In: Barstow M; (eds.). Kluwer, Dordrecht, p. 237

Liebert J., Wesemael F., Hansen C.J., et al., 1986, ApJ 309, 241
Liebert J., Dahn C.C., Monet D.G., 1988, ApJ 332, 891

Liebert J., Wesemael F., Husfeld D., Wehrse R., Starrfield S.G., Sion E.M., 1989, AJ 97, 1440

McCook G.P., Sion E.M., 1987, ApJS 65, 603

Motch C., Werner K., Pakull M.W., 1993, A\&A 268, 561

Nelan E.P., Wegner G., 1985, ApJ 289, L31

Oke J.B., Weidemann V., Koester D., 1984, ApJ 281, 276

Shipman H.L., 1979, ApJ 228, 240

Thejll P., Vennes S., Shipman H.L., 1991, ApJ 370, 355

Vennes S., 1992, ApJ 390, 590

Wegner G., Nelan E.P., 1987, ApJ 319, 916

Wegner G., Swanson S.A., 1991, ApJS 75, 507

Werner K., 1991, A\&A 251, 147

Werner K., Heber U., 1991, A\&A 247, 476

Werner K., Heber U., Hunger K., 1991, A\&A 244, 437

Wesemael F., Green R.F., Liebert J., 1985, ApJS 58, 379

Wesemael F., Greenstein J.L., Liebert J., et al., 1993, PASP 105,761 